\title{
ЯВЛЕНИЯ ИЗОМЕРИЗАЦИИ ПРИ КАТАЛИТИЧЕСКОИ ПЕРЕРАБОТКЕ АРОМАТИЧЕСКИХ УГЛЕВОДОРОДОВ
}

На современном этапе развития химической индустрии в органическом синтезе нспользуется большое количество индивидуальных ароматических соединений, на базе которых изготовляют химические волокна, пластмассы, пластификаторы, моющие вещества и многие другие химические продукты. Е. Берков [1] отмечает, что в настоящее время производство полимерных материалов из ароматических соединений превышает производство цветных металлов. Количество полимерных материалов непрерывно возрастает и через 20-25 лет превысит нынешннй уровень пронзводства стали.

Источниками ароматических соединений служат каменноугольная смола, нефть; смола высокотемпературного разложения горючих сланцев и другие виды сырья. Из них можно выделить бензол, толуол, ксилол, нафталин и антрацен, но большая часть используемых при синтезе ароматнческих соєдинений получается при различных химических процессах (ароматизация, ацилирование, аминирование, восстановление), большинство которых представляют собой каталитические процессы. Қатализаторов, которые в настоящее время используются в промышленности, очень много. Среди них можно назвать синтетические алюмосиликаты, очень много окисей, хлоридов и сульфидов металлов, металлы платиновой группы и т. д. При использовании катализаторов наряду с основной реакцией имеет место явление изомеризации, которое мешает шолучению ароматических соединений строго определенной структуры.

Изучая и зная эти явления, мы можем устранить их или использовать для синтеза.

П. Сергеев [2] отмечает, что уже в 1884 г. Аншютс изучал возможность диспропорционирования этилбензола в диэтилбензол в присутствии $\mathrm{AICI}_{3}$. Используя $30 \%$ $\mathrm{AICI}_{3}$ и нагревая этилбензол до $120-130^{\circ} \mathrm{C}$, он получил до $20 \%$ диэтилбензола, который, по его данным, состоял главным образом из параизомера. Более поздние данные показали, что полученный диэтилбензол содержит $60 \%$ метаизомера, а ортоизомер практически отсутствует. При этом отмечается, что продление реакции выше часа не оказывает существенного влияния на реакцию диспропорционирования.

А. Лин и Мак Колей [3] указывают, что при использовании $\mathrm{BF}_{3}$ вместо $\mathrm{AICI}_{3}$ уже при низких температурах образуется смесь бензола и метадиэтилбснзола. Они разработали методику непрерывного ведения процесса. При анализе продуктов для определения положения этильной группы использовали окисление $\mathrm{KMnO}_{4}$ в щелочной среде, а также гипохлоритом кальция и кислородом воздуха. Разделение образовавшихся изо- и терефталевых кислот производили по методике, основанной на различной растворимости кальциевых солей этих кислот в воде.

Исследования А. Топчиева $\left[{ }^{4}\right]$ показали, что, используя в качестве катализатора 
молекулярное соединение $\mathrm{BF}_{3} \cdot \mathrm{H}_{3} \mathrm{PO}_{4}$, удается получить преимущественно парадиалкилбензолы с незначительной примесью ортопроизводных.

Г. Пайнес и Г. Гофман [5] изучали изомеризацию ароматических и олефиновых углеводородов и пытались выяснить механизм этой реакции. По их мненню, в случае алкилароматических соединений возможны три вида изомеризации:

1) преобразование скелета алкильной группы;

2) изомеризация положения алкильной группы в ядре;

3) диспропорционирование алкильных групп между углеродными атомами ядра, причем получаются более замещенные алкнлбензолы.

Авторы отмечают, чтэ реакции первого и второго типов пронсходят в присутствин кислот; реакции второго и трегьего типов - в присутствии гидроизомеризующих катализаторов. Например, изомеризация вторичного бутилбензола происходит при $350^{\circ}$ и давлении 40 aтм в присутствии катализатора, которым может быть осажденная на окиси алюминия кремнефосфорная кислота или $\mathrm{ZnCl}_{2}$. Реакция происходит с промежуточным образоьанием иона карбония.

Изомеризация положения наблюдается в присутствии таких катализаторов, как $\mathrm{BF}_{3}, \mathrm{AlCl}_{3}, \mathrm{H}_{3} \mathrm{PO}_{4}$ и алюмосиликаты. При этом в случае низкой концентрацни катализатора получается смесь изомеров, близкая к термодинамически рассчитанной, а в случае более высоких концентраций получается почти 100\%-ный выход метадиалкилбензолов.

Р. Кинней [ $\left[\right.$ также отмечает, что при обработке бутилбензола при $100^{\circ}$ в прнсутствии хлористого алюминия получаются диалкилбензолы с содержанием $90 \%$ метаднбутилбензола.

Аналогичное явление наблюдается и в случае более замещенных алкилбензолов. Так, из три- : тетраметилбензолов при использовании малого количества катализатора получаются 1, 2, 4-триметилбензол и 1, 2, 4, 5-тетраметилбензол. При избыточном количестве катализатора образуются $1,3,5$ - три- и 1, 2, 3, 5-теграметилбензолы также почти со $100 \%$-ными выходами.

Г. Пайнес ["] объясняет механизм этих реакций следующим образом: алкилароматические углеводороды образуют с сильными кислотами комплексные соединения

$$
\begin{aligned}
& \mathrm{Ar}+\mathrm{HBr}+\mathrm{Al}_{2} \mathrm{Br}_{6} \rightarrow \mathrm{ArH}^{+}+\mathrm{Al}_{2} \mathrm{Br}_{7}^{-} \\
& \mathrm{Ar}+\mathrm{HF}+\mathrm{BF}_{3} \rightarrow \mathrm{ArH}^{+}+\mathrm{BF}_{4}^{-} \\
& \mathrm{Ar}+\mathrm{HCl}+\mathrm{Al}_{2} \mathrm{Cl}_{6} \rightarrow \mathrm{ArH}^{+}+\mathrm{Al}_{2} \mathrm{Cl}_{7}^{-}
\end{aligned}
$$

Получаемые соединения являются так называемыми $\sigma$-комплексами и образуются с присоединением протона. Считают, что такая связь образуется между углеродом бензольного ядра и протоном кислоты. Термодинамически рассчитано, что из всех возможных $\sigma$-комплексов изомеризации подвергается лишь тот, в котором связь образовалась с углеродным атомом ядра, связапным и с алкильной группой. После образования метаксилола комплекс становится стабильным и миграция алкильных групп прекращается. Из сказанного также следует, что в присутствии щелочेных катализаторов изомеризации скелета не происходит.

П. Эммег [7], рассматривая катализаторы, находит, что наиболее распространенными катализаторами кзомеризации являются хлюриды металлов и другие галогениды. Из них используются $\mathrm{AlCl}_{3}, \mathrm{AlBr}_{3}, \mathrm{BF}_{3}, \mathrm{FeCl}_{3}, \mathrm{~J}_{2}, \mathrm{MgCl}_{2}, \mathrm{ZnCl}_{2}$ и $\mathrm{MgBr}_{2}$. Из кислот наиболее часто используются серная кислота, $\beta$-толуолсульфоновая, хлорсульфоновая, фторсульфоновая, этансульфоновая, нафталинсульфоновая, фосфорная и другие. Часто используются сульфиды и окислы таких металлов, как $\mathrm{Al}, \mathrm{Cr}, \mathrm{Ti}, \mathrm{Mo}, \mathrm{Mg}, \mathrm{Th}, \mathrm{Cs}$. Используются и активные земли, причем активность их в отношении реакции изомеризации увеличивается при обработке минеральными кислотами [8].

Более подробные данные по изомеризации отдельных ароматических соединений в присутствии различных катализаторов приводит В. Коптюг [8]. 


\section{Экспериментальная часть}

В настоящей работе для изучения процесса изомеризации использовали хлориды металлов и их смеси, синтетические алюмосиликаты, окись алюминия и другие катализаторы.

Опыты проводили с толуолом и этилбензолом. Состав продуктов реакции определялся хроматографически. Реакции проводились в жидкой фазе при атмосферном давлении, в автоклаве под давлением и в паровой фазе, пропуская пары ароматического соединения через слой катализатора.

Изомеризация в жидкой фазе. Опыты проводили в колбе, снабженной мешалкой. Температура во всех случаях была $75^{\circ} \mathrm{C}$ и продолжительность 5 ч, что по данным литературы достаточно для достижения равновесия при изомеризации. Результаты опытов приведены в табл. 1.

Кроме катализаторов, указанных в таблице, опыты проводились также в присутствии $20 \% \mathrm{ZnCl}_{2}, 40 \% \mathrm{ZnCl}_{2}, 1 \% \mathrm{AlCl}_{3}+9 \% \mathrm{ZnCl}_{2}$, $20 \% \mathrm{CoCl}_{2}, 10 \% \mathrm{SiCl}_{4}, 10 \% \mathrm{MnCl}_{2}, 10 \% \mathrm{SrCl}_{2}, 10 \% \mathrm{TiCl}_{4}, 20 \% \mathrm{CuCl}_{2}$, $20 \% \mathrm{NiCl}_{2}$ и $25 \% \mathrm{FeCl}_{3}$. При использовании этих катализаторов при $75^{\circ}$ явления изомеризации не наблюдалось. Процесс алкилирования в присутствии $\mathrm{AlCl}_{3}$ часто проводится при $30^{\circ}$. При этой температуре и использовании $40 \% \mathrm{AlCl}_{3}$ изомеризации толуола не происходит.

Таблица 1

Результаты изомеризации в жидкой фазе

\begin{tabular}{|c|c|c|c|c|c|}
\hline & \multicolumn{5}{|c|}{ Номер опыта } \\
\hline & 1 & 2 & 3 & 4 & 5 \\
\hline Катализатор & $\mathrm{AlCl}_{3}$ & $\mathrm{AlCl}_{3}$ & $\mathrm{AlCl}_{3}$ & $\underset{\mathrm{TiCl}_{4}}{\mathrm{AlCl}_{3}+}$ & $\mathrm{AlBr}_{3}$ \\
\hline $\begin{array}{l}\text { Количество } \\
\text { катализатора, \% } \\
\text { Ароматическое соеди- } \\
\text { нение }\end{array}$ & 10 & 20 & $\begin{array}{c}45 \\
\text { Тол у о }\end{array}$ & $10+10$ & 10 \\
\hline \multicolumn{6}{|l|}{$\begin{array}{l}\text { Состав продуктов } \\
\text { реакции, \%: }\end{array}$} \\
\hline $\begin{array}{l}\text { бензол } \\
\text { толуол } \\
\text { м-ксилол }\end{array}$ & $\begin{aligned} & 5,3 \\
& 94,7 \\
& \text { Следы }\end{aligned}$ & $\begin{array}{c}8,0 \\
92,0 \\
\text { Следы }\end{array}$ & $\begin{array}{r}12,0 \\
79,4 \\
8,6\end{array}$ & $\begin{array}{c}6,1 \\
93,9 \\
\text { Следы }\end{array}$ & $\begin{array}{c}3,1 \\
96,9 \\
\text { Следы }\end{array}$ \\
\hline $\begin{array}{l}n \text {-ксилол } \\
o \text {-ксилол }\end{array}$ & $\ddot{0}$ & 0 & $\begin{array}{c}\text { Следы } \\
0\end{array}$ & 0 & $\ddot{0}$ \\
\hline
\end{tabular}

Из табл. 1 видно, что при изомеризации толуола образуется смесь ксилолов, в которой преобладает $м$-ксилол. При $75^{\circ} \mathrm{AlBr}_{3}$ оказывает более слабое изомеризующее действие, чем $\mathrm{AlCl}_{3}$. Увеличение количества $\mathrm{AlCl}_{3}$ с 20 до $45 \%$ не оказывает существенного влияния на степень изомеризации толуола и, следовательно, такое увеличение не может иметь практического значения.

Для увеличения степени изомеризации необходимо было повышение температуры, что потребовало проведения опытов в автоклаве.

Изомеризация под давлением. Был использован качающийся автоклав объемом $0,5 \Omega$ с электрическим обогревом. Продолжительность опытов - 5 ч. Результаты экспериментов приведены в табл. 2.

Кроме катализаторов, приведенных в таблице, опыты проводились также с $20 \% \mathrm{ZnCl}_{2}$ и $20 \% \mathrm{TiCl}_{4}$ при $260^{\circ}$ и 25 атм; при этом использо- 
Таблица 2

Результаты изомеризации под давлением

\begin{tabular}{|c|c|c|c|c|c|c|}
\hline & \multicolumn{6}{|c|}{ Номер опыта } \\
\hline & 6 & 7 & 8 & 9 & 10 & 11 \\
\hline $\begin{array}{l}\text { Катализатор } \\
\text { Количество катализатора, \% } \\
\text { Температура, }{ }^{\circ} \mathrm{C} \\
\text { Давление, атм } \\
\text { Ароматическое соединение }\end{array}$ & $\begin{array}{l}\mathrm{AlCl}_{3} \\
20 \\
180 \\
5\end{array}$ & $\begin{array}{l}\mathrm{AlCl}_{3} \\
20 \\
220 \\
14 \\
\mathrm{~T} 0 \mathrm{~J}\end{array}$ & $\begin{array}{l}\mathrm{AlCl}_{3} \\
10 \\
260 \\
25 \\
\pi\end{array}$ & $\begin{array}{r}\mathrm{AlBr}_{3} \\
20 \\
180 \\
5\end{array}$ & $\begin{array}{l}\mathrm{AlCl}_{3} \\
5 \\
260 \\
18 \\
\text { Этил }\end{array}$ & $\begin{array}{l}\mathrm{AlCl}_{3} \\
10 \\
260 \\
18 \\
\text { нзол }\end{array}$ \\
\hline \multicolumn{7}{|l|}{$\begin{array}{c}\text { Состав продуктов } \\
\text { реакции, \%: }\end{array}$} \\
\hline $\begin{array}{l}\text { бензол } \\
\text { толуол } \\
\text { м-ксилол } \\
n \text {-ксилол } \\
o \text {-ксилол } \\
\text { этилбензол } \\
\text { диэтилбензол }\end{array}$ & $\begin{array}{c}6,4 \\
90,4 \\
2,0 \\
1,2 \\
\text { С.еды } \\
- \\
-\end{array}$ & $\begin{array}{r}11,6 \\
71,9 \\
2,9 \\
2,2 \\
3,0 \\
5,6 \\
2,8\end{array}$ & $\begin{array}{r}11,2 \\
74,2 \\
3,4 \\
1,4 \\
2,3 \\
4,5 \\
3,0\end{array}$ & $\begin{array}{c}16,7 \\
70,5 \\
2,9 \\
2,2 \\
\text { Следы } \\
7,7 \\
\end{array}$ & $\begin{array}{r}28,6 \\
9,1 \\
- \\
- \\
5 \overline{5}, 0 \\
7,3\end{array}$ & $\begin{array}{r}28,4 \\
12,1 \\
- \\
\overline{-} \\
50,2 \\
9,3\end{array}$ \\
\hline
\end{tabular}

ванный толуол не подвергался изомеризации. При использовании $20 \% \mathrm{ZnCl}_{2}$ не происходит даже изомеризации этилбензола.

Из данных табл. 2 видно, что при $180^{\circ}$ и 5 aтм $\mathrm{AlBr}_{3}$ оказывает уже значительно большее изомеризующее действие, чем $\mathrm{AlCl}_{3}$. Отсюда следует, что изомеризующее действие катализатора зависит также от условий проведения опытов.

При проведении опытов под давлением также образуются преимущественно метаизомеры. Увеличение количества $\mathrm{AlCl}_{3}$ с 5 до $10 \%$ (опыты 10,11$)$ при прочих равных условиях не повышает сколько-нибудь значительно степени изомеризации. В известной мере новым является то, что в опытах под давлением наряду с другими образуются ортоизомеры. Интересно отметить, что из этилбензола ксилолы не образуются, хотя происходит изомеризация $50 \%$ этилбензола. Главными продуктами являются в этом случае бензол, толуол, а также диэтилбензол.

Изомеризация в паровой фазе (табл. 3, 4). Пары ароматических соединений пропускали через заполненную катализатором трубку длиной $80 \mathrm{~cm}$. Объемная скорость составляла 1 г ароматического соединения на 5 г катализатора в час.

Таблица 3

Опыты с палочкообразным алюмосиликатным катализатором

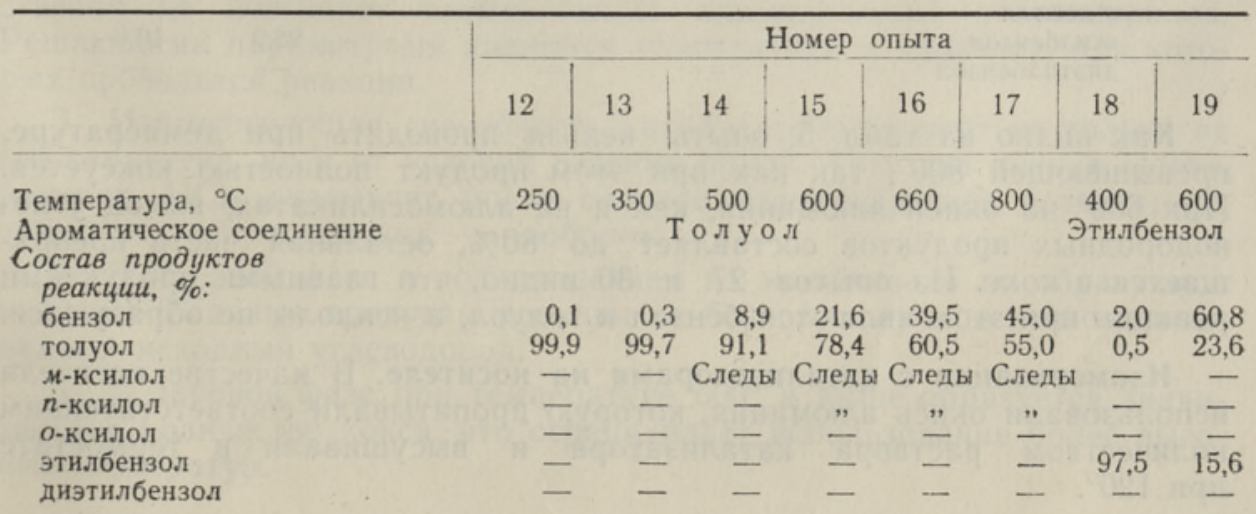


Опыты с шариковым алюмосиликатным катализатором

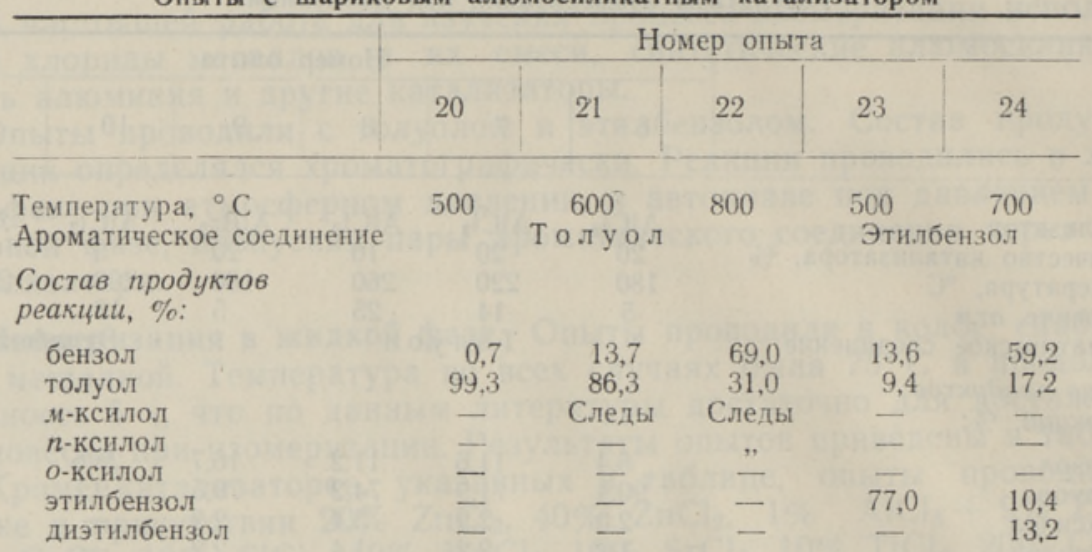

Следует отметить, что при использовании алюмосиликатных катализаторов в паровой фазе из этилбензола не образуется ксилолов. Основными продуктами реакции являются бензол, толуол и неизомеризованный исходный углеводород. При этом палочкообразный алюмосиликатный катализатор более активен при низких температурах, а шариковый - при более высоких температурах.

Изомеризация с окисью алюминия. Использовалась гранулированная окись алюминия марки АI ГОСТ 8186-56. Методика та же, что и в опытах с алюмосиликатами.

Таблица 5

Результаты изомеризации над окисью алюминия

\begin{tabular}{|c|c|c|c|c|c|}
\hline & \multicolumn{5}{|c|}{ Номер опыта } \\
\hline & 26 & 27 & 28 & 29 & 30 \\
\hline $\begin{array}{l}\text { Температура, }{ }^{\circ} \mathrm{C} \\
\text { Ароматическое } \\
\text { соединение }\end{array}$ & \multicolumn{3}{|c|}{ Толуол } & \multicolumn{2}{|c|}{ Этилбензол } \\
\hline \multicolumn{6}{|l|}{$\begin{array}{l}\text { Состав продуктов } \\
\text { реакции, \%: }\end{array}$} \\
\hline бензол & - & 35,0 & $\begin{array}{l}\text { Продукт } \\
\text { коксуется }\end{array}$ & 1,1 & 60,8 \\
\hline толуол & 100 & 65,0 & & 0,9 & 29,2 \\
\hline м-ксилол & - & - & & - & - \\
\hline $\begin{array}{l}n \text {-ксилол } \\
\text {-ксилол }\end{array}$ & - & - & & - & - \\
\hline $\begin{array}{l}\text { O-ксилол } \\
\text { этилбензол }\end{array}$ & - & $\overline{-}$ & & $\overline{98,0}$ & $\overline{10,0}$ \\
\hline диэтилбензол & - & - & & - & - \\
\hline
\end{tabular}

Как видно из табл 5, опыты нельзя проводить при температуре, превышающей $800^{\circ}$, так как при этом продукт полностью коксуется. При $600^{\circ}$ на окиси алюминия, как и на алюмосиликатах, выход углеводородных продуктов составляет до $80 \%$, остальная часть превращается в кокс. Из опытов 27 и 30 видно, что главными продуктами реакции при этом являются бензол и толуол, а ксилолы не образуются.

Изомеризация с катализаторами на носителе. В качестве носителя использовали окись алюминия, которую пропитывали соответствующим количеством раствора катализатора и высушивали в термостате Іри $120^{\circ}$. 
Первая серия опытов, приведенная в табл. 6, проводилась с $\mathrm{ZnCl}_{2}$.

Таблица 6

Результаты изомеризации над $\mathrm{ZnCl}_{2}$ на носителе

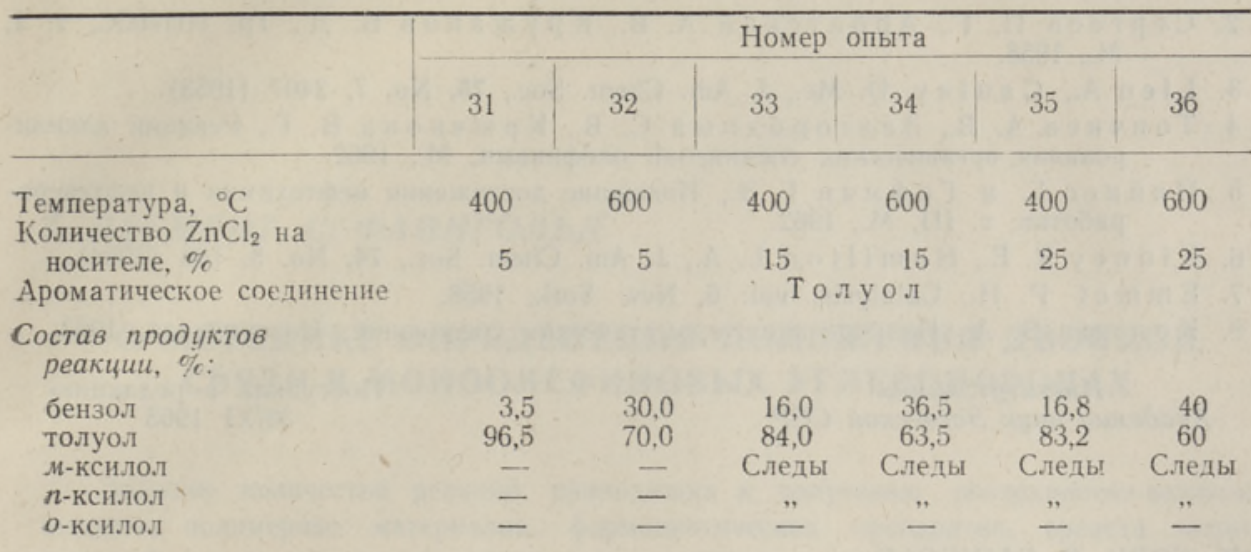

Данные табл. 6 позволяют сделать вывод, что при использовании $\mathrm{ZnCl}_{2}$ можно до $40 \%$ толуола перевести в бензол, причем ксилолы практически не образуются. Оптимальной концентрацией $\mathrm{ZnCl}_{2}$ является при этом 5-15\%. Можно использовать температуру до $600^{\circ}$.

Следует отметить, что использование $\mathrm{ZnCl}_{2}$ существенного эффекта не дает, так как аналогичные результаты были получены и с чистой окисью алюминия.

Наконец был проведен также целый ряд опытов с катализатором на носителе при 400-600', причем использовали $10 \% \mathrm{AlBr}_{3}, 20 \% \mathrm{AlBr}_{3}$, $10 \% \mathrm{Cu}_{2} \mathrm{Cl}_{2}, 10 \% \mathrm{NiCl}_{2}, 10 \% \mathrm{CoCl}_{2}$ и $10 \% \mathrm{FeCl}_{3}$. Во всех случаях были получены результаты, аналогичные приведенным, т. е. при $400^{\circ}$ выход бензола составлял $5-15 \%$, а при $600^{\circ}-30-40 \%$ без образования ксилолов.

\section{Выводы}

1. Изучена изомеризация толуола и этилбензола в жидкой и газовой фазах и под давлением в присутствии различных промышленных катализаторов: окиси алюминия, алюмосиликатов и хлоридов металлов.

2. Увеличение количества катализатора выше оптимального существенно не повышает изомеризацию ароматических углеводородов. Решающими параметрами являются температура и давление, при которых проводится реакция.

3. Изомеризующая способность катализатора зависит не только от его характера, но и от условий ведения опыта. Так, при низких температурах $\mathrm{AlCl}_{3}$ оказывает более сильное изомеризующее воздействие, чем $\mathrm{AlBr}_{3}$, а при высоких - наоборот.

4. В паровой фазе и под давлением из этилбензола пе образуются ксилолы. Главные продукты реакции - бензол, толуол и неизомеризованный исходный углеводород.

5. В паровой фазе при температуре $600^{\circ}$ и выше образуется значительное количество кокса, что ограничивает использование более высоких температур. 


\section{Л ИТЕРАТУРА}

1. Берков Е. А., Значение полимерных материалов в народном хозяйстве СССР, M., 1960.

2. Сергеев П. Г., Арбатский А. В., Кружанов Б. Д., Тр. НииСС, т. І, M., 1958.

3. Lien A., Caulay D. Mc., J. Am. Chem. Soc., 75, No. 7, 2407 (1953).

4. Топчиев А. В., З авгородный С. В., Крючкова В. Г., Реакцня алкилирования органических соединений олефинами, М., 1962.

5. П ай нес Г. и Гофм а Г. Э., Новейшие достижения нефтехимии и нефтепереработки, т. III, М., 1962.

6. Kinney R. E., Hamilton L. A., J. Am. Chem. Soc., 74, No. 3, 786 (1954).

7. Emmet P. H., Catalysis, vol. 6, New York, 1958.

8. Коптюг В. А., Изомеризация ароматических соедннений, Новосибирск, 1963.
Институт химии
Академии наук Эстонской ССР
Поступила в редакцию $30 / \mathrm{XI} 1965$

\section{KORV, S. FAINGOLD}

\section{ISOMERISATSIOONIN.XHTUSI AROMAATSETE SUSIVESINIKE KATALUUTILISEL TOOTLEMISEL}

Aromaatsete süsivesinike kataüütilise töötlemisega kaasneb sageli isomerisatsiooninähtusi, mis muudavad saadavate keemiliste ühendite struktuuri. Töös käsitletakse tolueeni ja etüülbenseeni isomerisatsiooni mitmesuguste katalüsaatorite manulusel, milleks olid alumiiniumoksiid, alumosilikaadid, metallide kloriidid jne. Märgitakse, et olulisteks isomerisatsiooni pôhjustavateks faktoriteks on temperatuur ja rōhk, mille juures reaktsioon läbi viiakse, kuna katalüsaatori hulga suurendamine üle optimaalse ei avalda olulist toimet. Leiti, et etüülbenseenist ei teki ksüleene, vaid peamisteks reaktsiooniproduktideks on benseen, tolueen ja lähtesüsivesinik, kuigi viimasest kuni $90 \%$ isomeriseerus. Samades tingimustes tekib tolueenist benseeni ja ksüleenide segu (ksüleenidest on valdavaks metaisomeer). Aromaatsete süsivesinike katalüütilise töötlemise temperatuur on piiratud $600^{\circ} \mathrm{C}$-ga; sellest kōrgemal tekib märgataval hulgal koksi.

\section{KORV, S. FAINGOLD}

\section{PHENOMENA OF ISOMERISATION AT CATALYTICAL PROCESSING OF AROMATIC HYDROCARBONS}

In catalytical processing of aromatic hydrocarbons, isomerisation phenomena are often involved, which change the structure of the chemical compounds obtained. The paper deals with the isomerisation of toluene and ethylbenzene resulting from processing with different catalysts, such as aluminium oxide, alumosilicates, metaI chlorides, etc. It has been stated that essential factors causing isomerisation are temperature and pressure at which the reaction is carried out, since the raising of the amount of catalyst above the optimum one is of no considerable consequence. It has been found that from ethylbenzene no xylenes are formed, but that the main products of the reaction are benzene, toluene and initial hydrocarbon (though about 90 per cent of the latter was isomerised). Under the same conditions, benzene and a mixture of xylenes are obtained from toluene (metaisomere being the predominant of xylenes). The temperature of the catalytical processing of aromatic hydrocarbons is limited to $600^{\circ} \mathrm{C}$; at higher temperatures, a considerable amount of coke is formed. 